\title{
Archiving Student Solutions with Tablet PCs in a Discussion-based Introductory Physics Class
}

\author{
Edward Price and Charles De Leone
}

Department of Physics, California State University San Marcos, San Marcos, CA 92096

\begin{abstract}
Many active learning based physics courses use whiteboards as a space for groups to respond to prompts based on short lab activities, problem solving, or inquiry-oriented activities. Whiteboards are volatile; once erased, the material is lost. Tablet PCs and software such as Ubiquitous Presenter can be used as digital whiteboards in active learning classes. This enables automatic capture and archiving of student work for online review by students, instructors, and researchers. We studied the use of digital whiteboards in an active-learning introductory physics course at California State University, San Marcos. In this paper we examine the archival features of digital whiteboards', and characterize the use of these features by students and instructors, and explore possible uses for researchers and curriculum developers.
\end{abstract}

Keywords: Computer supported collaborative learning, archive, Tablet PC, Ubiquitous Presenter.

PACS: 01.40.Fk, 01.50.ht, 01.20.+x

\section{INTRODUCTION}

Many PER-inspired curricula utilize collaborative small group work and whole class discussions. In practice, students often use whiteboards as a workspace for responding to instructor prompts and as a medium for presenting results to the rest of the class. Thus, the whiteboard contains a co-constructed response that differs from the work of any single individual. Once a whiteboard is erased, however, its contents are lost and no longer accessible to students, instructors, or researchers/curriculum developers. In contrast, with computers students can create work that is stored digitally. Software and web tools can then be employed to transmit and archive students' work for later access via the web. As a result, computermediated collaboration "turns communication into substance," [1] creating a record of co-created in-class work. Ready access to students' work can be valuable to students, instructors, and researchers/curriculum developers. In this paper, we document how students and instructors used archived student work in a particular physics class, and present an example showing the power of such an archive to researchers.

\section{SETTING AND METHODS}

As part of a broader study of how instructional tools (such as whiteboards or computers) influence classroom practices, we studied a classroom where Tablet PCs and Ubiquitous Presenter (UP) served as an alternative to whiteboards. A Tablet PC is a type of laptop computer with a stylus that can be used to "write" on the screen. UP is a Tablet PC-based system developed at the University of California, San Diego [2]. With UP, students access workspace through a web interface and use ink or text to create a response. In this way, a Tablet PC essentially becomes a digital whiteboard connected to the instructor via UP. At any time, students can send their work to the instructor, who can preview, project, and annotate submissions from any of the groups in the class. Furthermore, the instructor can create and write on blank slides, thereby using the system to lecture [3]. Finally, all student submissions, instructor slides, and added ink are automatically archived stroke by stroke and can be reviewed synchronously via a web interface.

We conducted a case study in an introductory physics course where students in two course sections used either whiteboards or Tablet PCs during the semester. Both sections spent equal time with each tool. One of us [CD] was the instructor for both sections. Data sources included classroom observations, instructor reflective notes, student interviews and surveys, students' in-class work, and server access logs.

The context for the study is Physics 205 at California State University, San Marcos. Physics 205 
is an introductory calculus-based physics course for students in the biological sciences. The class meets twice weekly, and each class meeting lasts 3 hours. The enrollment during this term was 42 students. Students work in an active learning environment with a small amount of integrated lecture. In a typical class meeting, students participate in a number of activities that are about 1 hour in length. Students work together in groups to respond to a series of prompts and then report their responses to their peers in a whole class discussion. Total lecture time is about 1 hour and 15 minutes per week and is used mainly to organize the students' ideas about phenomena they encountered in their group activities.

\section{RESULTS}

First, we describe how students and the instructor in Physics 205 used the archive of in-class work. We focus on the way students and the instructor used online material when whiteboards would not have been available, i.e., outside of class or after the whiteboards would have been erased. We then provide an example of how such an archive could be useful to researchers and curriculum developers.

\section{Student Use of Archived Material}

Students had to create an account to access materials archived online; students were encouraged to do so, and all but one did. Online material included students' in-class work as well as slides created by the instructor while lecturing. Student work accounted for about $84 \%$ of all slides. Students valued both types of material; $75 \%$ reported access to other students' work was useful or very useful, and $88 \%$ reported access to the instructor's slides was useful or very useful. Server $\operatorname{logs}$ indicated that students extensively viewed both student work and instructor slides. Of the more than 12,500 total server hits for both sections, 56\% were hits on slides created by students.

Figure 1 shows a histogram of the number of server hits, in units of the total number of pages. (Note, however, that server hits are not necessarily unique page views; if a student views the same page twice, this counts as two server hits.) For each section, approximately 375 individual pages (either student work or instructor slides) were available online. Approximately $24 \%$ of students had 125 or fewer server hits, 46\% had between 125 and 375 server hits, and $29 \%$ of the students had over 375 server hits. This is reasonably consistent with students' survey responses; $20 \%$ reported infrequently or hardly ever reviewing in-class material online, $15 \%$ reported

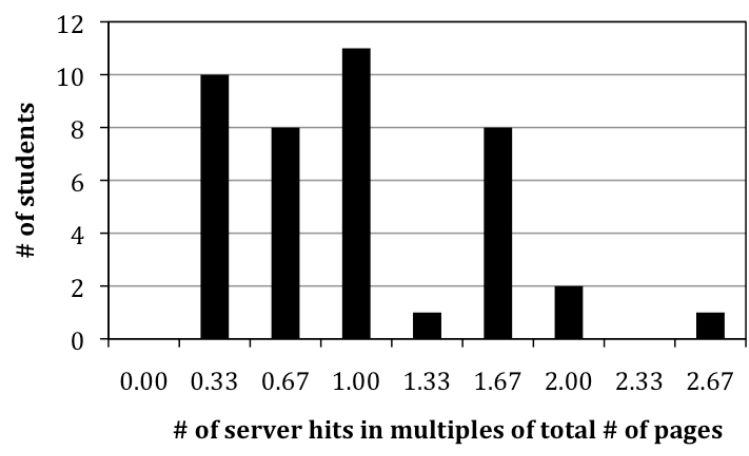

FIGURE 1. Histogram showing number of server hits by student, in multiples of the total number of pages (375). Both sections are included, a total of 41 students.

occasionally doing so, and $65 \%$ reported frequently or almost always doing so. When asked to select reasons for viewing online material, $76 \%$ indicated reviewing for a test or quiz, $66 \%$ indicated solving homework problems, and $29 \%$ indicated checking notes from a missed class. The pattern of server hits by date for one section, shown in Figure 2, indicates a pattern of sustained usage throughout the semester, with peaks near quizzes.

In interviews and open-ended survey questions, students described the value of online access to inclass materials. Near the end of the semester, after students had used both whiteboards and Tablet PCs with UP, students were asked to vote on which to use for the remainder of the semester. The vote was $60 \%$ to $40 \%$ in favor of Tablet PCs with UP. Asked to explain their choice in an open-ended question, 17 of the 23 students who voted for Tablet PCs with UP mentioned online access to in-class materials, making it by far the most commonly cited reason. One student commented, "I can't explain how convenient it is to be able to go online at home and print class work," while another said, "I sometimes didn't have time to write

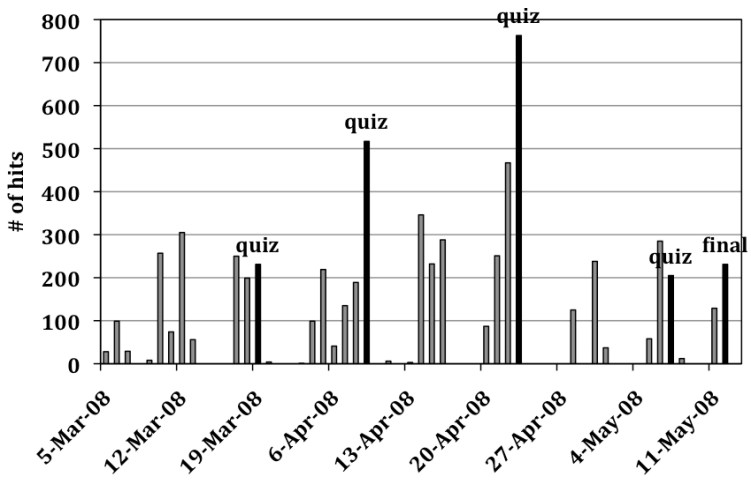

FIGURE 2. Number of daily server hits during the semester for a section of Physics 205 that began using Tablet PCs and UP on March 5. Quiz and final exam dates are indicated with labels and darker bars. Spring break is not included. 
down all of the class notes and I would go online and print them." Among students voting for whiteboards, the most commonly given reasons were more engagement and greater visibility during group problem solving sessions. Based on students' survey responses on the value of online access, it is plausible that some students who voted to use the whiteboards nevertheless found online access to materials valuable.

Lastly, students used archived material in class. Both an external evaluator and the instructor noted instances of students referring to previous work online while working on a new in-class activity. Students initiated this practice without instructor prompting.

\section{Instructor Use of Archived Material}

The archive of in-class materials was valuable to the instructor in Physics 205 as well as the students. First, the instructor could refer to archived student work during discussions with students outside of class. Students brought printed copies of in-class work to office hours, and the entire archive was available online for instructor and students to explore together.

During in-class discussions and lecture, the instructor could use the online archive to browse, choose, and project relevant student work, even from activities done several classes prior. With whiteboards, it was only possible to show student work for the most recently completed activity - work on previous activities already having been erased. Similarly, students could resume a partially completed activity at the beginning of the next class session. With whiteboards, student work was generally erased between class sessions. The ability to suspend and resume an activity increased the instructor's flexibility in conducting class.

Lastly, archived student work allowed the instructor to easily use students' in-class group work for formative assessment. During class, the instructor focused on facilitation, and could often carefully evaluate only groups that presented their work to the whole class. Archived student work made it possible for the instructor to review student work between classes, and then make adjustments to the following class based on the nature of the student work.

\section{Value to Researchers and Developers}

Student work - including work done in class - has been a vital source of data to physics education researchers and curriculum developers. Collecting students' in-class work, however, can disrupt the classroom and pose logistical challenges. Automatic archiving of students' classroom work facilitates the collection of this data. First, it is logistically easier and less intrusive than collecting paper copies or photographing whiteboards. Second, material is archived as part of normal class activities, and remains available even if interest in the material develops after the course is over. With an archive of students' inclass work throughout a course, researchers can assess student thinking on a particular concept or track development in students' abilities throughout a course. Curriculum developers could use an archive to evaluate student interpretation of an activity, sample student responses to use as examples in instructor support materials, determine the range and frequency of different student responses to a particular prompt, or evaluate students' progress on an activity within a given time limit. In this section, we illustrate some of these possibilities with an example from Physics 205.

The Physics 205 curriculum was originally developed at UC Davis and the course activities were explicitly informed by results of physics education research [4]. For instance, research on students' understanding of motion and graphing was consulted during the development of motion graphing activities. In one activity, students are asked to graph the position of the head and heel of a walking person as a function of time. Research in the area of physics education has pointed out that many students have difficulties connecting motion in the real world to its abstract representation on a graph [5].

Figure 3 shows a sample of work created by groups in response to this prompt. The top response is correct for the lab frame, while the bottom response is correct for a reference frame that moves with the person. The middle response, however, shows the heel never falling behind the head, and discontinuous motion of the heel. While this response is broadly consistent with published findings, familiarity with the research may not enable curriculum developers to anticipate this particular response. Knowledge of this specific student difficulty (in graphing the relation of the heel to the head of someone walking), and its prevalence, would be useful for curriculum developers designing appropriate follow-up activities. Such information would also be useful in developing suggestions on how to best facilitate a class discussion about such an activity.

Capturing work from all groups can provide greater insight into the range of student thinking on a single topic, such as the fairly sophisticated (for this course) use of reference frames suggested by lower response in Figure 3. In addition, the use of Tablet PCs and UP makes it easy to develop a database of student responses to a sequence of activities and track student progress throughout a semester. 


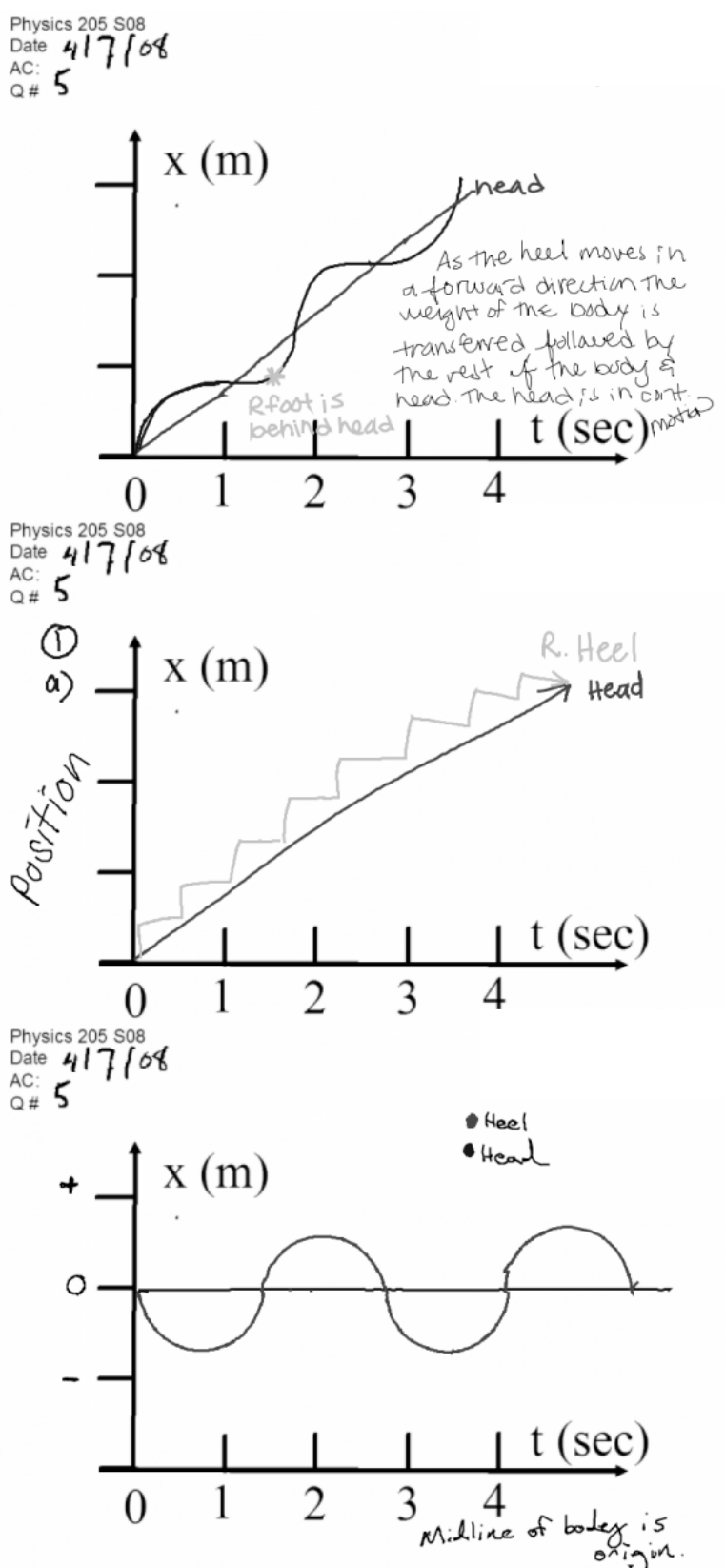

FIGURE 3. Student position versus time graphs for the motion of a walking person's head and heel. In the lower graph, the origin is taken as the midline of the person's body.

\section{CONCLUSION}

Many PER-inspired curricula emphasize in-class activities and discussions. The products of students' work - and instructor led discussions - have special meaning to the participants. As Suthers observed, "jointly constructed representations become imbued with meanings for the participants by virtue of having been produced through a process of negotiation [6]." In most cases, however, materials created during class are lost or unavailable once class is over. In Physics 205 , both students and the instructor utilized archived materials when they were made available. In class, students and instructor used the archive to access students' previous work. Outside of class, students heavily accessed the materials to review for quizzes and to do homework. Notably, students viewed considerable numbers of student-generated pages. The instructor used the archive outside of class as a referent in discussions with students, and as a means of formative assessment and pedagogical refinement. Researchers and curriculum developers interested in accessing student responses from a classroom setting could also use the seamless capture and archiving of student work.

In this study, the archived materials were simply made available to students, without guidance on their use. In the future, it would be possible to design structured activities utilizing the archived material, such as reflective activities requiring students to evaluate others' solutions. Such activities could make archived material even more valuable.

\section{ACKNOWLEDGMENTS}

Thanks to Robin Marion, John Saunders, the Ubiquitous Presenter team at UC San Diego (especially James Lintern for assistance analyzing server logs), and CSUSM's Instructional and Information Technology Services. Additionally, this work was made possible, in part, by a grant from Hewlett Packard.

\section{REFERENCES}

1. Dillenbourg, P. "Designing Biases That Augment SocioCognitive Interactions," in Barriers and Biases in Computer-Mediated Knowledge Communication, Bromme, R., Hesse, F.W., and Spada, H., eds. Springer Netherlands, 2005, pp 243-264.

2. More info on UP can be found at http://up.ucsd.edu (accessed June 29, 2008). UP is based on Classroom Presenter, developed at the University of Washington.

3. Price, E., Malani, R., and Simon, B. "Characterization of Instructor and Student Use of Ubiquitous Presenter, a Presentation System Enabling Spontaneity and Digital Archiving," 2006 Physics Education Research Conference, in AIP Conference Proceedings 883 125128, (2006).

4. De Leone, C.J., Potter, W.H., and Coleman, L.B. "Radically Restructured Introductory Physics Course at a Large Research University," in The Changing Role of Physics Departments in Modern Universities, Part One, AIP Press, p. 829, (1996).

5. See, for example, McDermott, L.C., Rosenquist, M.L., and van Zee, E.H. Am. J. Phys. 55, 503-513 (1987).

6. Suthers, D.D. Int. J. CSCL 1, 315-337 (2006). 